\section{Trends in Gout Hospitalization in Sweden}

\section{To the Editor:}

Gout is the most common arthritic disease in the world, with increasing incidence. An increase in hospitalization for gout has been shown for the last 2 decades in North America ${ }^{1,2}$. We evaluated the trend for hospitalization of gout in western Sweden from 2002 to 2012 and compared it to the total hospitalization rate.

Hospitalization trends for gout were studied using data from the healthcare consumption register in the Western Swedish Health Care Region (WSHCR) from January 1, 2002, through December 31, 2012. Patients 18 years and older were included who were hospitalized during the study period with a principal discharge International Classification of Diseases (10th ed) diagnosis of gout (M10), and all unique hospitalizations were identified. We calculated annual population rates of hospitalization for gout. Dispensations of the urate-lowering therapies (ULT) allopurinol (M04AA01) and probenecid (M04AB01) were identified for the 6 months preceding and following the hospitalization, through the Swedish Prescribed Drug Register $^{3}$. Costs for the hospitalizations were retrieved from the Cost Per Patient register from 2009 to 2012, while earlier years are not available. Data for total hospitalization were retrieved from the National Board of Health and Welfare statistical database for inpatient care ${ }^{4}$. Ethical approval for the study was granted from the Ethical Review Board of Gothenburg, Sweden (347-13).

There were 1601 hospitalizations for gout (mean age 74.3-77.6 yrs, 60-74\% men, 106-192 unique patients per yr) between 2002 and 2012. Demographic characteristics were similar over the study period. From 2002 to 2012, the annual hospitalization rate for gout increased significantly from 9.5 to 16.7 per 100,000 adults (Figure 1 and Table 1). The duration per hospitalization also increased from 3 to 5 days, median 2002 and 2012, respectively. Only a minority of patients, $19 \%$ to $27 \%$ per year, received ULT in the 6 months preceding their hospitalization while a larger proportion received ULT the following 6 months (23\% to 56\%). From 2009 to 2012 the inflation-adjusted total annual healthcare costs for gout hospitalizations in this region increased from US\$5.21 to $\$ 8.15 \times 10^{5}$ (Table 1).

These findings should be mirrored against opposite trends for hospitalization in the general population, for which the total number of days for inpatient care in the WSHCR decreased by $9 \%$ from 2002 (1343, 120 days, mean duration 6.8 days) to $2012(1268,127 \text { days, mean duration } 5.6 \text { days })^{4}$. There was only a modest increase $(6 \%)$ in the total annual hospitalization rate, from 17,348 to 18,376 per 100,000 adults. Similar trends for overall care were seen for the whole of Sweden ${ }^{4}$.

One limitation of our study is that by focusing on principal discharge diagnoses, we may have missed hospitalizations in which gout was a contributing factor. Second, our case definition was based on diagnoses of gout made in the clinical situation rather than according to the different proposed classification criteria, which may have led to misclassification bias. On the other hand, we identified only the principal discharge diagnosis, which probably reduces such misclassification.

A strength of the study is that the mandatory health registers in Sweden, with virtually complete coverage on an individual level, make the results population-representative. Second, the estimates for ULT treatment and hospitalizations were retrieved from independent data sources.

We have previously shown that overall incidence of gout is increasing in this region ${ }^{5}$ and that ULT is scarce in the same region ${ }^{6}$. Now, in addition to this, we show that gout leading to hospitalization is increasing while ULT remains insufficient.

MATS DEHLIN, MD, PhD; LENNART T.H. JACOBSSON, MD, Professor, Department of Rheumatology and Inflammation Research, Sahlgrenska Academy, University of Gothenburg, Sweden. Address correspondence to Dr. M. Dehlin, Department of Rheumatology and Inflammation Research, Guldhedsgatan 10A, University of Gothenburg, S-413 45 Gothenburg, Sweden.E-mail: mats.dehlin@vgregion.se

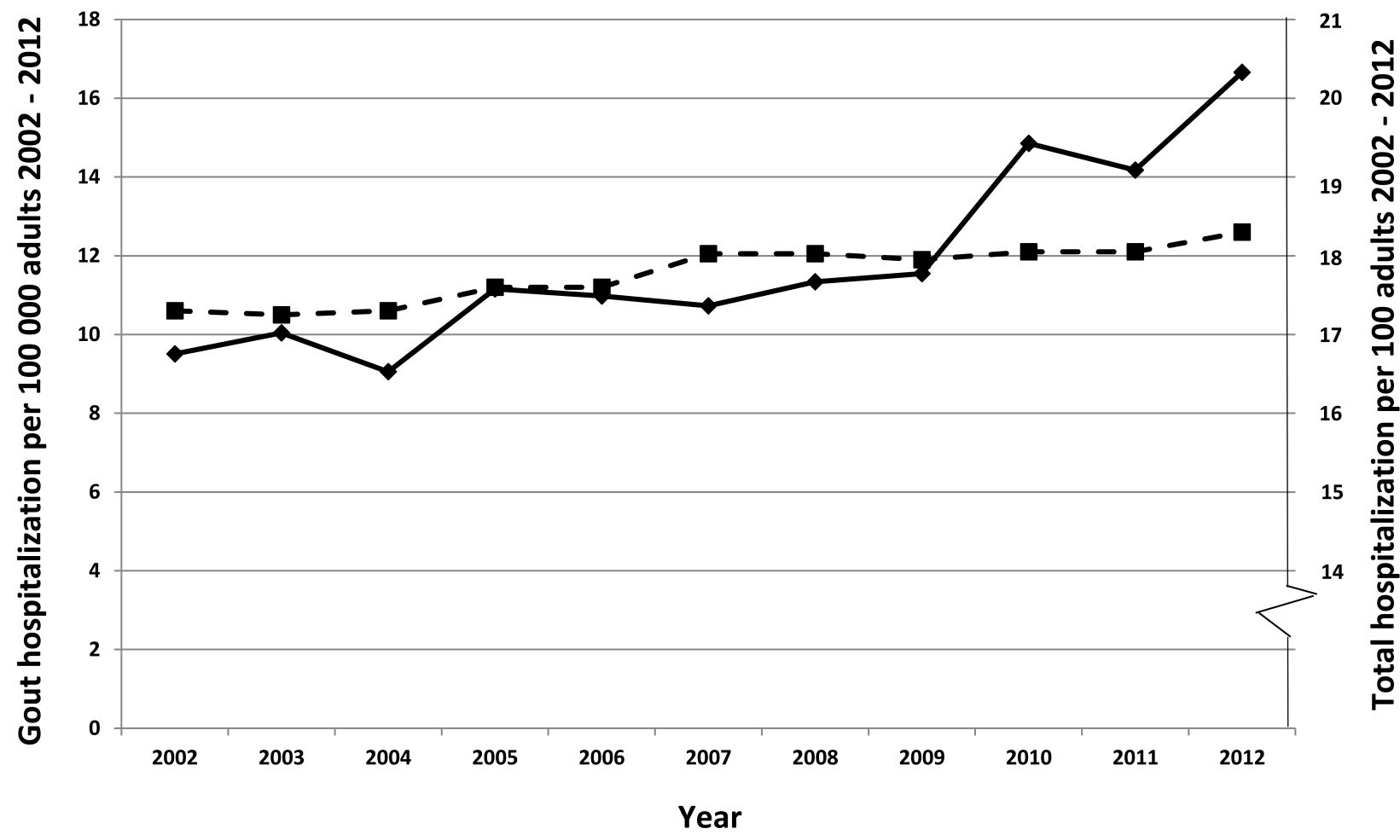

Figure 1. Annual hospitalization rate for gout per 100,000 adults, and the total hospitalization rate per 100 adults, 2002-2012. The solid line shows the rate for gout and the dashed line shows the rate for total hospitalization. 
Table 1. Hospitalizations for gout and all causes, 2002 to 2012.

\begin{tabular}{|c|c|c|c|c|c|c|c|c|c|c|c|c|}
\hline & 2002 & 2003 & 2004 & 2005 & 2006 & 2007 & 2008 & 2009 & 2010 & 2011 & 2012 & $\mathrm{p}^{*}$ \\
\hline Discharges for gout, $\mathrm{n}$ & 112 & 119 & 108 & 134 & 133 & 131 & 140 & 144 & 187 & 180 & 213 & \\
\hline \multicolumn{13}{|c|}{ Gout hospitalization, incidence } \\
\hline per 100,000 adults & 9.5 & 10.0 & 9.1 & 11.2 & 11.0 & 10.7 & 11.3 & 11.5 & 14.9 & 14.2 & 16.7 & 0.0002 \\
\hline $\begin{array}{l}\text { Total hospitalization, } \\
\text { per } 100,000 \text { adults }\end{array}$ & $\begin{array}{l}\text { cidence } \\
17,348\end{array}$ & 17,269 & 17,369 & 17,656 & 17,689 & 18,147 & 18,186 & 17,971 & 18,278 & 18,178 & 18,376 & $<0.0001$ \\
\hline \multicolumn{13}{|c|}{ Gout hospitalization, incidence } \\
\hline \multicolumn{13}{|c|}{ Gout hospitalization, incidence } \\
\hline per 100,000 women & 6.8 & 7.0 & 5.3 & 8.9 & 7.7 & 6.5 & 7.0 & 7.1 & 7.9 & 7.3 & 9.1 & 0.14 \\
\hline $\begin{array}{l}\text { Gout hospitalization d } \\
\text { median (range) }\end{array}$ & $\begin{array}{l}\text { Iration, days } \\
3(1-44)\end{array}$ & $4(1-99)$ & $5(1-75)$ & $4(1-36)$ & $5(1-65)$ & $4(1-34)$ & $5(1-40)$ & $5(1-39)$ & $5(1-34)$ & $5(1-52)$ & $5(1-41)$ & \\
\hline $\begin{array}{l}\text { Total hospitalization d } \\
\text { median (range) }\end{array}$ & $\begin{array}{l}\text { aration, days } \\
3(0-8614)\end{array}$ & $3(0-2610)$ & $3(0-3273)$ & $3(0-4759)$ & $3(0-7452)$ & $3(0-2666)$ & $3(0-2737)$ & $3(0-5332)$ & $3(0-7383)$ & $3(0-7624)$ & $3(0-3026)$ & \\
\hline $\begin{array}{l}\text { Age at gout hospitaliz } \\
\text { mean (SD) }\end{array}$ & $\begin{array}{l}\text { tion, yrs, } \\
74.3(14.9)\end{array}$ & $77.5(10.9)$ & $76.3(11.7)$ & $75.8(12.3)$ & $77.2(10.2)$ & $76.2(13.0)$ & $77.4(11.4)$ & $76.7(11.6)$ & $77.6(12.7)$ & $75.6(14.1)$ & $75.0(13.8)$ & \\
\hline \multicolumn{13}{|c|}{ Gout hospitalization by age group, yrs } \\
\hline $18-44$ & 6 & 5 & 1 & 2 & 0 & 6 & 5 & 4 & 8 & 8 & 4 & \\
\hline $45-64$ & 16 & 12 & 17 & 22 & 19 & 15 & 12 & 11 & 19 & 28 & 41 & \\
\hline $65-84$ & 63 & 73 & 67 & 75 & 80 & 82 & 85 & 89 & 100 & 92 & 108 & \\
\hline$\geq 85$ & 27 & 29 & 23 & 35 & 34 & 28 & 38 & 40 & 60 & 52 & 60 & \\
\hline ULT, $(\%), 6$ mos befor & discharge & & & & $28(21)$ & $28(21)$ & $38(27)$ & $27(19)$ & $38(20)$ & $47(26)$ & $45(21)$ & \\
\hline ULT, $(\%), 6$ mos after & discharge & & & & $31(23)$ & $64(49)$ & $78(56)$ & $35(24)$ & $103(55)$ & $83(46)$ & $94(44)$ & \\
\hline Total cost**, $10^{5}$ US\$ & & & & & & & & 5.21 & 6.8 & 6.6 & 8.15 & \\
\hline
\end{tabular}

* P value for trend calculated by linear regression. ** Adjusted for inflation. ULT: urate-lowering therapy.

\section{REFERENCES}

1. Rai SK, Avina-Zubieta JA, McCormick N, De Vera MA, Lacaille D, Sayre EC, et al. Trends in gout and rheumatoid arthritis hospitalizations in Canada from 2000 to 2011. Arthritis Care Res 2017;69:758-62.

2. Lim SY, Lu N, Oza A, Fisher M, Rai SK, Menendez ME, et al. Trends in gout and rheumatoid arthritis hospitalizations in the United States, 1993-2011. JAMA 2016;315:2345-7.

3. Socialstyrelsen. Läkemedelsregistret. [Internet. Accessed October 24, 2017. Web page in Swedish.] Available from: http:// www.socialstyrelsen.se/register/halsodataregister/lakemedelsregistret
4. The National Board of Health and Welfare. Statistical database for diagnosis in in-ward care. [Internet. Accessed October 23, 2017. Web page in Swedish.] Available from: www.socialstyrelsen.se/ statistik/statistikdatabas/diagnoserislutenvard

5. Dehlin M, Drivelegka P, Sigurdardottir V, Svard A, Jacobsson LT. Incidence and prevalence of gout in Western Sweden. Arthritis Res Ther 2016;18:164.

6. Dehlin M, Ekstrom EH, Petzold M, Stromberg U, Telg G, Jacobsson LT. Factors associated with initiation and persistence of urate-lowering therapy. Arthritis Res Ther 2017;19:6.

J Rheumatol 2018;45:1; doi:10.3899/jrheum.170381 